For publication in the Proceedings of the Fourth International Laser Science Conference (ILS-IV) (Advances in Laser Sciences - IV) Mariott Marquis Hotel, Atlanta, Georgia, October 2-6, 1988, to be published by the American Institute of Physics

CONF-881002--30

DE89 004165 0

\title{
TWO-PHOTON RESONANT, STIMULATED PROCESSES IN KRYPTON AND XENON*
}

\author{
John C. Miller \\ Chemical Physics Section, Oak Ridge National Laboratory, \\ Oak Ridge, Tennessee 37891-6125
}

November 1988

*Research sponsored by the Office of Health and Environmental Research, U.S. Department of Energy under contract DE-AC84OR21400 with Martin Marietta Energy Systems, Inc.

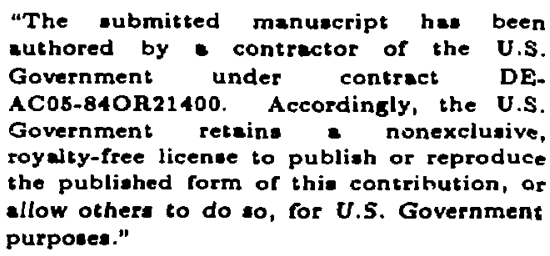

\section{DISCLAIMER}

This report was prepared as an account of work sponsored by an agency of the United States Government. Neither the United States Government nor any agency thereof, nor any of their employees, makes any warranty, express or implied, or assumes any ligal liability or responsibility for the accuracy, completeness, or usefulness of any information, apparatus, product, or process discloced, or represents that its use would not infringe privately ownod rights. Reference herein to any specific commercial product, process, or service by trade name, trademark, manufacturer, or otherwive does not necesuarily constitute or imply its endorsement, recommendation, or favoring by the United States Government or any agency thereof. The views and opinione of authors expresed berein do not necesearily state or reflect those of the United States Government or any agency thereof. 


\title{
TWO-PHOTON RESONANT, STIMULATED PROCESSES IN KRYPTON AND XENON
}

\author{
John C. Miller \\ Chemical Physics Section, Oak Ridge National Laboratory \\ P.O. Box 2008, Oak Ridge, Tennessee, 37831-6125
}

ABSTRACT

Both on-axis and conical emissions have been observed following two-photon pumping of the $5 \mathrm{p}$ states of krypton and the $6 \mathrm{p}^{\prime}, 7 \mathrm{p}, 8 \mathrm{p}$, and $4 \mathrm{f}$ states of xenon. In the former case, coherent emissions from the $5 p$ states to the 5s are observed and in the latter case, many $\mathrm{p} \rightarrow \mathrm{s}, \mathrm{d} \rightarrow \mathrm{p}$, and $\mathrm{f} \rightarrow \mathrm{d}$ cascade emissions are observed. By analogy to the well-studied alkali and alkaline earth examples, the emissions are discussed in terms of amplified spontaneous emission (ASE), stimulated hyper-Raman scattering, and parametric four-wave mixing. The physical processes responsible for the conical emission and for intensity anomolies in the xenon $\mathrm{p} \rightarrow \mathrm{s}$ emissions are not understood at present. Interference effects due to coherent cancellation between competing excitation pathways may be occurring.

\section{INTRODUCTION}

Ever since the first report in 1967 of the production of coherent vacuum ultraviolet radiation via third-harmonic generation (THG) in rare gases, techniques for increasing its efficiency have been explored. ${ }^{1}$ The use of twophoton resonance enhancement of the non-linear susceptibility was recognized very early for metal vapor systems. ${ }^{1}$ Along with the increased efficiency of THG, however, came the observation that a panoply of competing non-linear processes also became important when exciting at or near two-photon resonance. These may include multi-photon ionization (MPI), stimulated electronic Raman scattering (SERS), stimulated hyper-Raman scattering (SHRS), and amplified spontaneous emission (ASE). These new emissions present in the laser focus can also interact with the pump radiation to generate new waves by a parametric four-wave mixing (PFWM) scheme.

In contrast to the accessability of the two-photon levels in metal systems, the corresponding studies in rare gases require intense, tunable, ultraviolet light (210-225 nm) which has only recently become available. The present paper presents the first results from a comprehensive study of these very interesting processes in krypton and xenon.

\section{EXPERIMENTAL}

The frequency-doubled beam of an excimer-pumped dye laser (Lambda Physik) is loosely focussed $(50 \mathrm{~cm})$ into an MPI cell with suprasil windows. The emerging light is refocussed into either an optical multichannel analyzer (VIS-IR), an infrared spectrometer and diode detector, or a vacuum ultraviolet spectrometer equipped with a solar-blind phototube. Rearrangement of the optics and addition of a dicroic mirror allowed detection of backward-directed light. More details may be found elsewhere. ${ }^{2}$ 


\section{RESULTS AND DISCUSSION}

\section{A. Krypton}

Two-photon excitation at 214.7 or $216.6 \mathrm{~nm}$ excites the $5 \mathrm{p}\left[\frac{3}{2}\right]_{2}$ and $5 \mathrm{p}\left[\frac{5}{2}\right]_{2}$ levels, respectively of Krypton (Figure 1). Once populated, these levels are inverted relative to the lower-lying $5 \mathrm{~s}^{\prime}$ and $5 \mathrm{~s}$ states. Amplified spontaneous emission to the former lies in the mid-infrared and was not observed. The latter emissions to both 5 s levels were observed in the forward and backward direction as shown in Figure 2 for the forward ASE. The relative intensity of the two lines are in accord with their calculated line strengths. ${ }^{3}$ The time profile of the emission ( $~ 8 \mathrm{~ns}$ ) is similar to that of the excitation laser pulse and shorter than the radiative lifetime of 20-50 ns. The emission was polarized with its polarization parallel to the input laser for $\Delta \mathrm{J}=1$ transitions and perpendicular for $\Delta \mathrm{J}=0$ transitions. The excitation spectrum of the ASE was very narrow (laser linewidth limited) and peaked at the $5 \mathrm{p}\left[\frac{3}{2}\right]_{2}$ or $5 \mathrm{p}\left[\frac{5}{2}\right]_{2}$ transition energies as monitored by $(2+1)$ MPI. No other emissions were observed for excitation on or near these levels. All of the above observations are consistent with the assignment of the emissions as ASE.

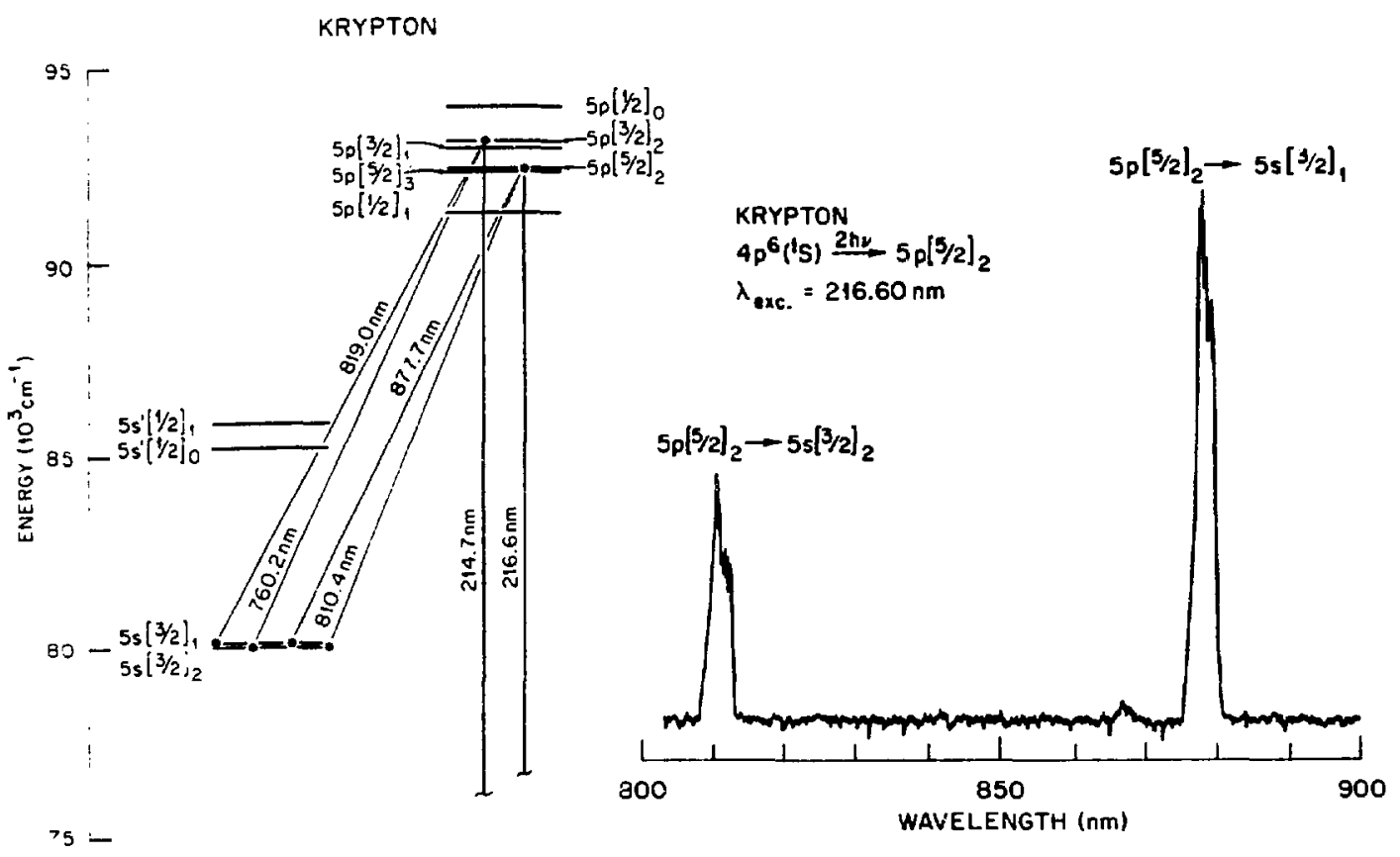

Figure 1.

Figure 2.

\section{B. Xenon}

In xenon the accessible tuning region overlaps the two-photon wavelengths for excitation of the $6 \mathrm{p}, 7 \mathrm{p}, 6 \mathrm{p}^{\prime}$, and $4 \mathrm{f}$ manifolds. Figure 3 shows the relative energies of these levels as well as a summary of the observed emissions. The straight arrows indicate emissions observed connecting the various manifolds. The wavy arrows indicate nonobserved emissions whose existence can be inferred from the observed "cascade" ASE. For most of the emissions the ohserved linestrenoths nolarizations and forward-hackward intensity ratios 


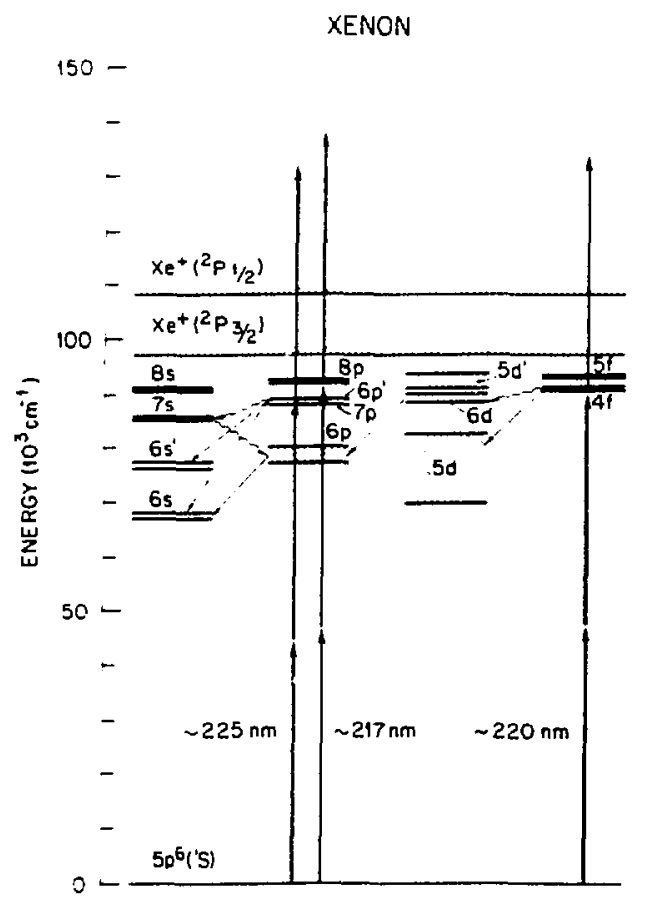

Figure 3.
Two anomolies were observed, however, which are presently not understood. First, for excitation of the $6 \mathrm{p}^{\prime}\left[\frac{3}{2}\right]_{2}$ and $7 \mathrm{p}\left[\frac{3}{2}\right]_{2}$ levels, only emission to the $6 \mathrm{~s}\left[\frac{3}{2}\right]_{2}$ state is observed. Emission to the corresponding $\mathrm{J}=1$ level is less than $5 \%$ although branching ratios from theory ${ }^{3}$ and spontaneous $^{4}$ fluorescence are more nearly equal. Furthermore, in the latter case emission to the $6 s^{\prime}\left[\frac{1}{2}\right]_{1}$ state should be observable based on the published branching ratios. The second anomoly concerns the visual observation of conical emission at higher pressures (100 torr) for the same two excitations. Although conical emission is usually associated with the phase-matching requirements of PFWM, this process is not possible in this case as the terminal level, the $6 s\left[\frac{3}{2}\right]_{2}$ state cannot optically connect to the ground state by dipole selection rules. Six-wave mixing processes can be envisioned, however.

Although not understood at the present time, the unusual ASE branching ratios and the presence of wave-mixing processes may implicate interference effects between various coherent pathways between states. Additional experiments are currently being performed in order to further characterize these two-photon resonant stimulated processes in rare gases.

Research sponsored by the Office of Health and Environmental Research, U.S. Department of Energy under contract DE-AC05-84OR21400 with Martin Marietta Energy Systems, Inc.

\section{REFERENCES}

1. C. R. Vidal in Tunable Lasers, L. F. Mollenauer and J. C. White, eds., (Springer-Verlag, Berlin, 1987), pp. 56-113.

2. P. R. Blazewicz and J. C. Miller, Phys. Rev. A $\underline{38}, 2863$ (1988); J. C. Miller, to be published.

3. M. Aymar and M. Coulombe, Atomic Data and Nuclear Data Tables 21, 537 (1978).

4. H. Horiguchi, R.S.F. Chang, and D. W. Setser, J. Chem. Phys. $\underline{75}, 1207$ (1981). 